\title{
Mechanisms of Cell Death Induced by the Mitochondrial Toxin 3- Nitropropionic Acid: Acute Excitotoxic Necrosis and Delayed Apoptosis
}

\author{
Zhen Pang and James W. Geddes \\ Sanders-Brown Center on Aging and Department of Anatomy and Neurobiology, University of Kentucky, Lexington, \\ Kentucky 40536-0230
}

Impaired energy metabolism may play an important role in neuronal cell death after brain ischemia and in late-onset neurodegenerative diseases. Both excitotoxic necrosis and apoptosis have been implicated in cell death induced by metabolic impairment. However, the factors that determine whether cells undergo apoptosis or necrosis are not known. In the present study, metabolic impairment was induced by 3-nitropropionic acid (3-NP), a suicide inhibitor of succinate dehydrogenase. Treatment of cultured rat hippocampal neurons with 3-NP resulted in two types of cell death with distinct morphological, pharmacological, and biochemical features. A rapid necrotic cell death, characterized by cell swelling and nuclear shrinkage, could be completely prevented by the NMDA receptor antagonist MK-801 (10 $\mu \mathrm{M})$ and dose-dependently potentiated by low micromolar levels of extracellular glutamate. A slowly evolving apoptotic death, characterized by nuclear fragmentation, was not attenuated by MK-801 but was prevented by cycloheximide $(1 \mu \mathrm{g} / \mathrm{ml})$. The combination of MK-801 and cycloheximide resulted in an almost complete protection against 3-NP-induced cell death. DNA fragmentation, detected by the terminal deoxynucleotidyl transferase-mediated dUTP-X $3^{\prime}$ nick end-labeling technique, was a late event in apoptosis and also occurred after necrotic cell death. ATP depletion was an early event in the 3-NP-induced neuronal degeneration, and the decline in ATP was exacerbated by glutamate. We conclude that 3-NP triggers two separate cell death pathways: an excitotoxic necrosis as a result of NMDA receptor activation and a delayed apoptosis that is NMDA receptor-independent. Mildly elevated levels of extracellular glutamate shift the cell death mechanism from apoptosis to necrosis.

Key words: energy metabolism; succinate dehydrogenase; 3-nitropropionic acid; excitotoxicity; apoptosis; necrosis; nuclear fragmentation; TUNEL; ATP
Neuronal function and survival depend on a continuous supply of glucose and oxygen, used to generate ATP through glycolysis and mitochondrial respiration. A perturbation in energy metabolism during conditions such as ischemia, stroke, and brain trauma may cause irreversible neuronal injury. An age-related decline in energy metabolism also may contribute to neuronal loss during normal aging, as well as in neurodegenerative diseases (Wallace, 1994; Beal, 1995).

There are discrepancies in the findings regarding the mechanisms of neuronal cell death after metabolic impairment. A large body of evidence supports the "secondary excitotoxicity" hypothesis that a loss of ATP leads to membrane depolarization, removal of the voltage-dependent $\mathrm{Mg}^{2+}$ block of the NMDA receptor, and subsequent activation of NMDA receptor (for review, see Beal, 1992). Both in vivo and in vitro studies have shown that metabolic inhibitors potentiate glutamate and NMDA toxicity (Weller and Paul, 1993; Greene and Greenamyre, 1995; Maragos and Silverstein, 1995; Marey-Semper et al., 1995). As a result, ambient glutamate can become neurotoxic when intracellular energy levels are reduced (Novelli et al., 1988; Zeevalk and Nicklas, 1991; Fu et

Received Nov. 13, 1996; revised Feb. 13, 1997; accepted Feb. 17, 1997.

This work was supported by National Institute on Aging Grant AG05144 and by an Alzheimer's Association/Estate of Ruby Hodges pilot research grant. We thank Vimala Bondada for excellent technical assistance. We also thank Dr. Mark P. Mattson for helpful discussions of this manuscript.

Correspondence should be addressed to James W. Geddes, 209 Sanders-Brown Building, University of Kentucky, Lexington, KY 40536-0230.

Copyright (C) 1997 Society for Neuroscience $0270-6474 / 97 / 173064-10 \$ 05.00 / 0$ al., 1995). In some studies, however, NMDA receptor antagonists attenuated but did not prevent neuronal death, suggesting that there is an NMDA-independent mechanism (Weller and Paul, 1993; Fink et al., 1996). Recently, Behrens and colleagues (1995) reported that 3-nitropropionic acid (3-NP), a suicide inhibitor of the mitochondrial enzyme succinate dehydrogenase (SDH) (Alston et al., 1977), induced apoptosis in neuronal cultures and that excitotoxicity was not involved.

Apoptosis and necrosis are two basic forms of cell death that are defined based on morphological and biochemical criteria (for review, see Majno and Joris, 1995). Apoptosis is characterized by cell body shrinkage, cytoplasmic and nuclear fragmentation (karyorrhexis), and internucleosomal chromatin cleavage. In contrast, necrosis is characterized by a rapid cell swelling and cell lysis, with random degradation of DNA (Wyllie et al., 1980). Apoptosis can often be blocked by inhibitors of gene transcription and translation, suggesting that it requires ongoing protein synthesis (Wyllie et al., 1984; Martin et al., 1988). Consistent with the notion that apoptosis is a gene-directed self-destruction program, alterations in gene expression are associated with apoptosis (for review, see Bredesen, 1995). Recent studies suggest that apoptosis contributes to neuronal cell death after cerebral ischemia (Nitatori et al., 1995; Chopp and Li, 1996; Du et al., 1996), in Alzheimer's disease (Cotman and Anderson, 1995; Lassmann et al., 1995; Anderson et al., 1996), and in Huntington's disease (Portera-Cailliau et al., 1995).

Because apoptosis and necrosis reflect two fundamentally different cell death mechanisms, it is important to determine whether cell death after impairment of energy metabolism occurs 
via apoptosis, necrosis, or both. We demonstrate that in primary cultures of rat hippocampal neurons, 3-NP triggers two cell death pathways: a rapid excitotoxic necrosis and a delayed apoptosis. The balance between the two depends on extracellular glutamate levels.

\section{MATERIALS AND METHODS}

Primary hippocampal neuronal cultures. Primary cultures of fetal rat (E18) hippocampal neurons were established according to the procedures of Brewer and colleagues (1993) with slight modifications. Pregnant Harlan Sprague Dawley rats (Harlan, Indianapolis, IN) were killed with halothane. Fetuses were removed using aseptic techniques. Fetal brains were removed and placed in HBSS without $\mathrm{Ca}^{2+}$ and $\mathrm{Mg}^{2+}$ (Life Technologies, catalog \#14180). Hippocampi were dissected and digested in HBSS containing $0.25 \%$ trypsin for $15 \mathrm{~min}$ at room temperature. The hippocampi were then washed with HBSS and incubated with mung bean trypsin inhibitor $(1 \mathrm{mg} / \mathrm{ml}$, Sigma) for $5 \mathrm{~min}$. Tissues were dissociated by repeated trituration in HBSS ( 8 hippocampi/ml) with a fire-polished pasteur pipette. Cells were seeded at $150-200$ neurons $/ \mathrm{mm}^{2}$ into poly-Dlysine $(50 \mu \mathrm{g} / \mathrm{ml}$, Sigma)-coated $35 \mathrm{~mm}$ culture dishes (Corning) containing Neurobasal supplemented with B27, glutamine, and glutamate (Life Technologies). The cultures were maintained at $37^{\circ} \mathrm{C}$ in a humidified incubator with $6 \% \mathrm{CO}_{2}$ and $94 \%$ air. After $4 \mathrm{~d}$ in culture, one-third of the medium was replaced with medium without glutamate. On the seventh day in vitro (7 DIV), cultures were rinsed with fresh medium. Treatment was initiated by adding concentrated stock solutions $(200-1000 \times)$ of 3-NP or other drugs into the culture medium with gentle mixing. 3-NP (Aldrich, Milwaukee, WI) and glutamate (Life Technologies) were dissolved in sterile water, with $\mathrm{pH}$ adjusted to 7.2 by adding concentrated $\mathrm{NaOH}$ solution. The noncompetitive NMDA receptor antagonist $(+)-5-$ methyl-10,11-dihydro-5H-dibenzo[a,d] cyclohepten-5,10-imine hydrogen maleate (MK-801, dizocilpine maleate) (Research Biochemicals International, Natick, MA) and the eukaryotic protein synthesis inhibitor cycloheximide (Sigma) were dissolved in sterile water without $\mathrm{pH}$ adjustment.

Assessment of neuronal cell death/survival. For assessment of cell viability of cultured neurons, a grid was etched on the bottom of the $35 \mathrm{~mm}$ culture dish. Before experimental treatment, phase-contrast photomicrographs were taken, with approximately 30-60 neurons present in each field (four fields per culture dish). Photos of the same fields (localized by the grid) were taken at various post-treatment time points. Viable neurons were identified by morphological criteria, including a smooth cell body and intact neurites. In pilot studies, cell viability was confirmed by testing cell membrane permeability [trypan blue or propidium iodide (PI) exclusion and fura-2 retention]. Cell survival was expressed as a percentage of the initial number of neurons. Two to three cultures per condition were used in each experiment. The experiments were repeated at least twice using separate preparations.

Quantitative analysis of apoptosis. After treatment, cultures were fixed with $4 \%$ paraformaldehyde and stained with PI $(5 \mu \mathrm{g} / \mathrm{ml}$ in PBS containing $0.1 \%$ Triton $\mathrm{X}-100)$. Cultures were coverslipped, and nuclear morphology was visualized with an epifluorescent microscope (Olympus $\mathrm{BH} 2$ ) with the filter set for rhodamine. Living cells displayed cytoplasmic staining and large, oval-shaped, evenly stained nuclei. Apoptotic cells were identified by the presence of fragmented nuclei (karyorrhexis), whereas necrotic cells had small and condensed nuclei. Apoptosis was first quantified as a percentage of apoptotic nuclei per total nuclei (500-750 cells per culture dish). This was necessary to determine whether the extent of apoptosis was above the background level observed in the absence of treatment. In addition, the percentage of apoptotic cell death, representing the proportion of apoptosis per total cell death events, was calculated using the following equation:

$$
A / D=\left(A-A_{\mathrm{o}}\right) /\left(A-A_{\mathrm{o}}+N\right),
$$

where $A_{\mathrm{o}}$ is the percentage of initial apoptotic cells estimated using sister cultures before treatment, $A$ is the percentage of apoptotic cells after treatment, $N$ is the percentage of necrotic cells after treatment, and $A / D$ is the percentage of apoptotic cell death induced by the treatment.

This equation was based on the observations that the naturally occurring cell death in these cultures was exclusively apoptotic and that when cells were plated at moderate density, almost all $(\sim 98 \%)$ of the dead cells remained attached to the culture substrate and were therefore available for assessment.

In situ detection of DNA fragmentation. The $3^{\prime} \mathrm{OH}$ ends resulting from
DNA degradation were detected with the terminal deoxynucleotidyl transferase-mediated dUTP-X 3' nick end-labeling (TUNEL) technique invented by Gavrieli and colleagues (1992). This was conducted using the In Situ Cell Death Detection kit (Boehringer Mannheim), according to the manufacturer's instructions. Briefly, cultures were fixed with $4 \%$ paraformaldehyde in PBS for $30 \mathrm{~min}$ and permeabilized with $0.25 \%$ Triton X-100 for 10 min. Cells were rinsed with PBS and covered with a labeling reaction mixture containing terminal deoxynucleotidyl transferase (TdT) and fluorescein-deoxyuridine triphosphate (dUTP). Cultures were incubated at $37^{\circ} \mathrm{C}$ for $1 \mathrm{hr}$. Reactions were terminated by rinsing the cells with PBS. For the correlation of TUNEL with nuclear morphology, cultures were counterstained with PI $(5 \mu \mathrm{g} / \mathrm{ml})$, coverslipped, and observed with an epifluorescent microscope. Photos were taken using a $40 \times$ objective. To confirm the specificity of TUNEL, cultures were treated with $1 \mu \mathrm{g} / \mathrm{ml}$ DNase I (Sigma) at room temperature for $10 \mathrm{~min}$ to create positive controls. TdT was omitted from the labeling reaction mixture in negative controls.

Determination of ATP levels. Cellular ATP levels were quantified using a luciferin/luciferase-based assay. Briefly, cultures were rinsed with PBS, and cells were lysed with $0.2 \mathrm{ml}$ of ATP releasing buffer (Sigma). ATP concentrations were measured using the ATP Bioluminescence Assay kit CH II (Boehringer Mannheim) and a luminometer (Optocomp I, MGM Instruments). A standard curve was created by measuring solutions of known ATP concentrations. Samples were diluted so that the readings fell within the linear range. Protein content was determined using the BCA protein assay (Pierce, Rockford, IL). ATP levels were expressed as nanomoles of ATP per milligram of protein for each sample.

Determination of extracellular glutamate concentration. The extracellular glutamate concentration in control cultures (7 DIV) was determined by reverse-phase HPLC. Samples of culture medium were extracted with absolute ethanol to remove proteins. After extraction, amino acids were derivatized with $o$-phthaldialdehyde/2-mercaptoethanol and injected onto a $\mathrm{C} 18$ column (Hewlett-Packard ODS Hypersil, $5 \mu \mathrm{m}, 200 \times 2.1 \mathrm{~mm}$ ). Derivatives of the amino acids were separated using a linear gradient of methanol $(25-70 \%)$ in potassium acetate $(0.1 \mathrm{M}, \mathrm{pH} 5.55)$ at a flow rate of $0.4 \mathrm{ml} / \mathrm{min}$. Column effluent was monitored using a Shimadzu RF-535 fluoromonitor with an excitation wavelength of $340 \mathrm{~nm}$ and an emission wavelength of 418 $\mathrm{nm}$. Standard curves for glutamate gave a linear relationship between the amount of fluorescence and the quantity of the amino acid applied to the column over a range of $1-100 \mu \mathrm{M}$.

Statistical analysis. Results are expressed as the mean \pm SEM. Tests for statistical significance included ANOVA followed by Scheffe's $F$ test for comparison of multiple experimental conditions or Student's $t$ test for comparison of two values.

\section{RESULTS}

\section{3-NP triggers acute necrosis and delayed apoptosis}

The experimental model used in the current study was dissociated rat hippocampal cell culture maintained in neurobasal/B27 medium. In this chemically defined serum-free medium, hippocampal cultures are more than $95 \%$ neuronal, based on microtubuleassociated protein 2 and glial fibrillary acidic protein (GFAP) immunostaining (results not shown). GFAP-immunopositive glial cells do not proliferate, and they acquire a process-bearing morphology that resembles mature astrocytes. In addition, there is a small percentage of microglial cells in the culture.

Treatment with 3-NP resulted in a dose-dependent decrease in the number of viable neurons when cell survival was assessed $48 \mathrm{hr}$ after treatment (Fig. 1). 3-NP did not affect the viability of non-neuronal cells (data not shown). Examination of neuronal survival at multiple time points revealed that some neurons underwent rapid cell death within several hours, whereas others underwent a slowly evolving cell death over the next $2 \mathrm{~d}$ (Fig. 2). These two types of temporally segregated cell death were designated as acute and delayed cell death, respectively. Apparently, the acute cell death occurred in a more synchronous manner than the delayed cell death.

To determine whether the cell death was necrotic or apoptotic, cultures were fixed and stained with PI. The background cell death in the untreated control cultures exhibited nuclear fragmen- 


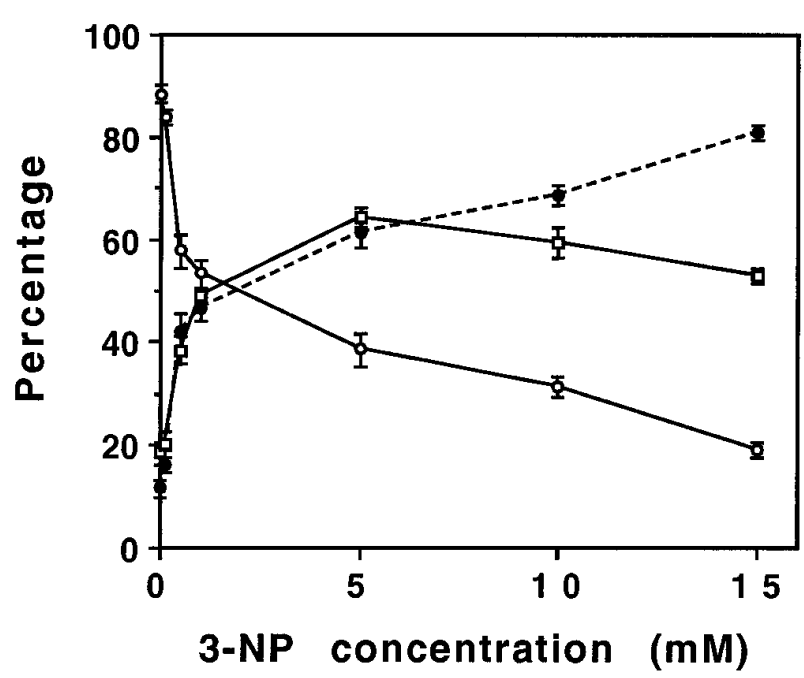

Figure 1. Dose-dependent effects of 3-NP on neuronal survival and induction of apoptosis. Cultured hippocampal neurons (7 DIV) were treated for $48 \mathrm{hr}$ with 3-NP. The percentages of neuronal survival (open circles), cell death ( filled circles with dashed line), and apoptotic cells (open squares) were assessed (see Materials and Methods). Results are the mean \pm SEM of six to nine cultures.

tation, a hallmark of apoptosis. On 7 DIV, approximately $13 \%$ of the cells were apoptotic. This number increased to $\sim 20 \%$ after 48 hr. After 3-NP treatment, many dead cells showed typical apoptotic nuclear morphology, whereas others had shrunken nuclei (Fig. 2). 3-NP increased the percentage of apoptotic neurons in a dose-dependent manner, with $5 \mathrm{~mm}$ being the most potent concentration for specifically inducing apoptosis (Fig. 1). The number of apoptotic cells started decreasing when 3-NP was used at higher concentrations, and an increased number of neurons exhibited nuclear shrinkage.

To further distinguish the acute versus the delayed cell death and to determine whether nuclear shrinkage represents necrotic cell death, morphological alterations were correlated with the time points of cell death. The acute cell death was preceded by cell body swelling and nuclear shrinkage, characteristic of neuronal necrosis (Fig. 2). Cell body swelling was evident within $1 \mathrm{hr}$ after 3-NP treatment. In contrast, the delayed cell death resulted in nuclear fragmentation, without early cell body swelling. Therefore, the acute cell death corresponding to nuclear shrinkage was necrotic, whereas the delayed cell death corresponding to nuclear fragmentation was apoptotic.

\section{Pharmacology of 3-NP toxicity}

To determine whether excitotoxicity was involved in 3-NPinduced cell death, the noncompetitive NMDA receptor antagonist MK-801 was added to the culture medium simultaneously with 3-NP. MK-801 effectively blocked the acute necrotic cell death. However, it was ineffective in preventing the delayed apoptosis (Fig. 3A). Instead, MK-801 slightly increased the percentage of apoptotic neurons, indicating that neurons rescued by MK-801 could then undergo apoptosis. Furthermore, MK-801 did not alter the rate of the delayed cell death (Fig. 4). These results demonstrated that the acute neuronal necrosis was mediated by the NMDA receptor, whereas the delayed apoptosis was NMDA-receptor-independent.

To determine whether 3-NP-induced apoptosis requires ongoing protein synthesis, cultures were treated with $3-\mathrm{NP}$ in the presence of the protein synthesis inhibitor cycloheximide. Unlike MK-801, cycloheximide did not affect the acute cell death. Analysis of nuclear morphology revealed that cycloheximide effectively blocked apoptosis but not necrosis (Fig. $3 A$ ). In fact, cycloheximide increased the percentage of necrotic cells, although cycloheximide alone was not toxic at $1 \mu \mathrm{g} / \mathrm{ml}$ for a period of $48 \mathrm{hr}$ (Fig. $3 B)$. It appeared that neurons continued undergoing necrotic cell death when apoptosis was blocked. Why some neurons treated with 3-NP underwent delayed necrosis in the presence of cycloheximide is not known. It is possible that these neurons became vulnerable to excitotoxicity as a result of decreased production of neuroprotective factors, such as calbindin.

Although the overall cell death was only partially reduced by either MK-801 or cycloheximide, a combination of these two agents resulted in an almost complete protection (Fig. 3B). These data strongly suggest that neurons were killed by two distinct and sometimes coexisting mechanisms.

To determine whether MK-801 and cycloheximide permanently blocked cell death, cultures were treated for $48 \mathrm{hr}$ with $3-\mathrm{NP}$ in the presence of MK-801 and cycloheximide. Then, drugcontaining medium was replaced by washing three times with the normal glutamate-free culture medium. Most neurons $(\sim 80 \%)$ underwent apoptosis within $24 \mathrm{hr}$, suggesting that these neurons were irreversibly injured and had become committed to apoptosis during the first $48 \mathrm{hr}$ of treatment.

\section{Effects of extracellular glutamate on 3-NP toxicity}

The basal level of extracellular glutamate was $4.3 \mu \mathrm{M}$, measured by HPLC. Addition of low micromolar levels of extracellular glutamate resulted in cell death that was clearly biphasic (Fig. 4). The acute cell death that occurred within the first $8 \mathrm{hr}$, but not the delayed cell death, was dose-dependently potentiated by exogenous glutamate $(5-20 \mu \mathrm{M})$ (Fig. 5A,B). The ability of glutamate to potentiate the acute cell death was completely abolished by MK801 (Figs. 4, 5A). These data provide further support for the interpretation that the acute cell death induced by 3 -NP was attributable to glutamate toxicity.

Glutamate itself at 10 and $20 \mu \mathrm{M}$ was only slightly toxic to the cultured neurons (Figs. 4, 5A,B), suggesting a synergistic interaction between glutamate and 3-NP. Glutamate alone had an acute but not delayed effect on neuronal survival. Quantitative analysis of apoptosis indicated that cell death induced by glutamate was necrotic (data not shown).

By promoting necrotic cell death, glutamate decreased the percentage of apoptotic cell death (Fig. 5C). With basal levels of glutamate, 3-NP-induced cell death was $\sim 80 \%$ apoptotic and $\sim 20 \%$ necrotic (Fig. $5 C$ ). When glutamate was added at $10 \mu \mathrm{M}$, cell death was $\sim 40 \%$ apoptotic and $\sim 60 \%$ necrotic. In the presence of MK-801, cell death was virtually all apoptotic. These data indicate that glutamate shifts the cell death mechanisms from apoptosis to necrosis by activating the NMDA receptor.

\section{Correlation of nuclear morphology with TUNEL staining}

The role of DNA fragmentation in cell death was studied using the TUNEL technique. Double labeling with PI and TdTmediated incorporation of fluorescein-dUTP at free $3^{\prime} \mathrm{OH}$ ends of DNA was conducted to correlate nuclear morphology with the presence of DNA strand breaks. TUNEL staining was specific for DNA damage, and it depended on TdT activity (Fig. 6A,B). All apoptotic nuclei under various culture conditions and at all time points were intensely TUNEL-labeled (Fig. $6 C-F$ ). However, 

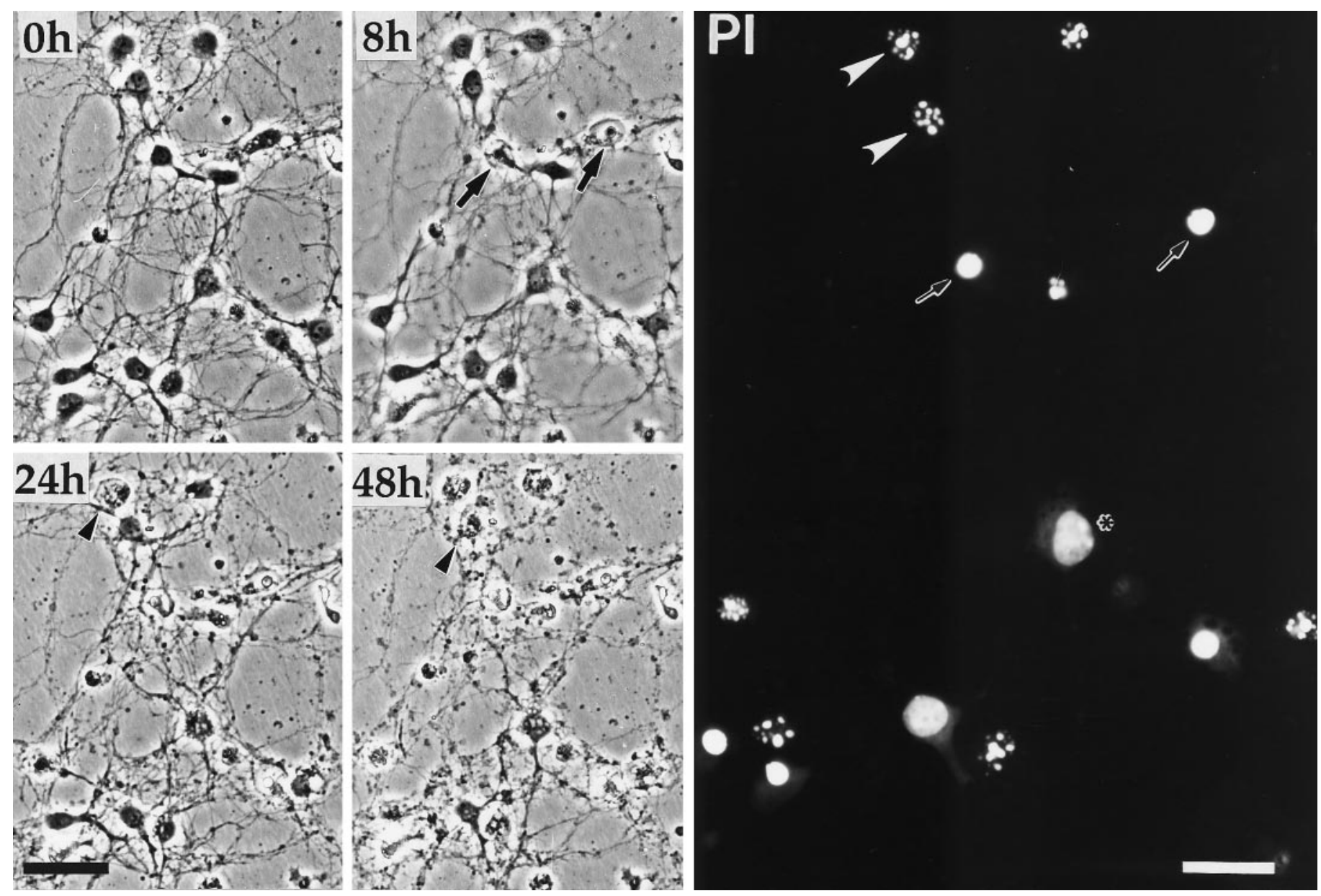

Figure 2. 3-NP induces both acute and delayed cell death. A culture was treated with $5 \mathrm{~mm}$ 3-NP. Phase-contrast photographs were taken just before 3-NP administration $(0 h)$ and 8,24 , and $48 \mathrm{hr}$ after 3-NP administration. The culture was then fixed in paraformaldehyde, stained with PI, and visualized under a fluorescent microscope using a rhodamine filter set ( far right). The acute cell death resulting in nuclear shrinkage is indicated by arrows, whereas the delayed cell death resulting in nuclear fragmentation is indicated by arrowheads. In contrast, the large and evenly stained nuclei belong to living neurons (asterisk). Note that cells remained attached to the substrate after death. These data are representative of four separate experiments. Scale bars: white, $25 \mu \mathrm{m}$; black, $50 \mu \mathrm{m}$.

TUNEL staining rarely labeled intact nuclei with a normal appearance, suggesting that DNA degradation was intimately associated with nuclear fragmentation, thus a late event in apoptosis.

It appeared that the TUNEL technique was not specific for apoptosis because $\sim 50 \%$ of necrotic nuclei were also stained at the $48 \mathrm{hr}$ time point, although the staining intensity was more variable compared with apoptotic nuclei (Fig. 6F). However, when TUNEL was conducted at earlier time points, few necrotic nuclei were labeled (Figs. $6 E, 7 A$ ). The negative labeling was not attributable to altered membrane permeability or complete degradation of nuclear DNA because these necrotic cells were strongly labeled with TUNEL after DNase I treatment (data not shown). The percentage of TUNEL-positive necrotic cells increased dramatically at later time points, although necrotic cell death had largely ceased by $8 \mathrm{hr}$ (Fig. 7B). These results demonstrate that DNA fragmentation occurs after the loss of cell viability in neuronal necrosis.

\section{Cellular ATP levels}

Cellular ATP levels were examined using a highly sensitive luciferase-based ATP assay. In control cultures, cellular ATP was $21.2 \pm 7.0 \mathrm{nmol} / \mathrm{mg}$ protein $(n=12)$. 3 -NP resulted in a time- dependent ATP loss (Fig. 8A). ATP levels were decreased by $\sim 25 \%$ at the $2 \mathrm{hr}$ time point, before cell death. The further decrease in ATP at later time points may be attributable in part to cell death. The early decline of ATP was reversed transiently by MK-801. However, by $8 \mathrm{hr}$, the 3-NP-induced decline in ATP was comparable in the presence and absence of MK-801. The transient ATP increase in the presence of MK-801 was consistently observed. However, the mechanism underlying this phenomenon is unknown.

When cultures were treated with 3-NP plus $10 \mu \mathrm{M}$ glutamate for $2 \mathrm{hr}$, ATP levels were reduced by $>50 \%$. Glutamate alone did not result in ATP loss (Fig. 8B). The exacerbation by glutamate of the 3-NP-induced decline in ATP was blocked by MK-801. Thus, 3-NP and glutamate synergistically reduced cellular ATP and induced rapid necrotic death in $\sim 60 \%$ of neurons (Figs. $4,5 D$ ).

Cycloheximide had little effect on the cellular ATP levels when measured at the $2 \mathrm{hr}$ time point (Fig. $8 B$ ). When cells were treated with 3-NP $(5 \mathrm{~mm})$ in the presence of MK-801 $(10 \mu \mathrm{M})$ and cycloheximide $(1 \mu \mathrm{g} / \mathrm{ml})$ for $48 \mathrm{hr}$, cellular ATP levels fell to $\sim 50 \%$ of untreated control cultures, although there was no difference in neuronal survival under these two culture conditions 
A

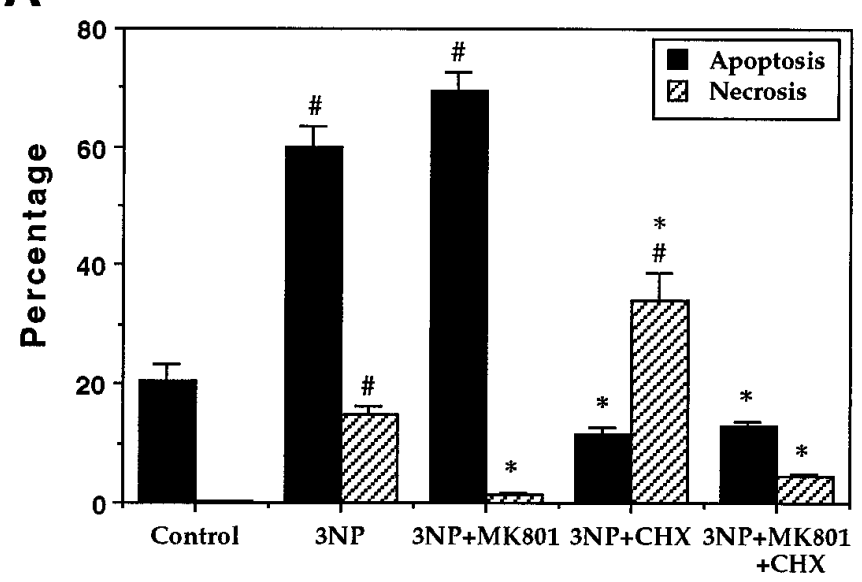

B

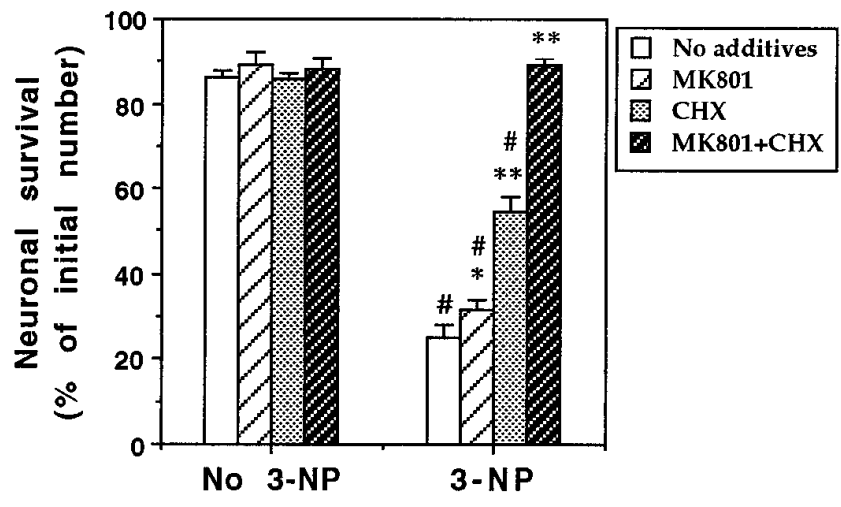

Figure 3. Protective effects of MK-801 and cycloheximide $(C H X)$ on 3 -NP toxicity. Cultures were treated under the indicated conditions for 48 hr. Drug concentrations were $5 \mathrm{~mm} 3-\mathrm{NP}, 10 \mu \mathrm{M}$ MK-801, and $1 \mu \mathrm{g} / \mathrm{ml}$ CHX. Values represent the mean \pm SEM of 8-14 cultures. $A$, Quantitation of apoptosis and necrosis. *, significantly different from 3-NP alone, $p<0.01$; \#, significantly different from control, $p<0.01$. $B$, MK-801 and cycloheximide, either alone or in combination, did not affect neuron survival in the absence of 3-NP. In 3-NP-treated cultures, MK-801 and cycloheximide had modest protective effects alone, but in combination they provided almost complete protection against neuronal death. Significantly different from 3 -NP alone $\left({ }^{*} p<0.05,{ }^{* *} p<0.01\right)$. \#, significantly different from corresponding control cultures, $p<0.01$.

(Fig. 3B). This indicated that the cycloheximide-mediated protection was not achieved by maintaining cellular ATP.

\section{DISCUSSION}

Despite numerous studies that have examined neuronal cell death after metabolic impairment, it remains uncertain (1) whether neurons die by necrosis, apoptosis, or both and (2) what the underlying mechanisms are. We demonstrate that in cultured rat hippocampal neurons, 3-NP-induced cell death occurs through two distinct pathways. One involves activation of the NMDA receptor, which leads to a rapid necrotic death. The other is a delayed, apoptotic death, which is NMDA receptor-independent. Moderate levels of extracellular glutamate shift the cell death pathway from apoptosis to necrosis.

The discrepancies among various previous studies (see introductory remarks) may be attributable, in part, to the assessment of cell death at a single time point. In the present study, cell death was inspected at both early ( 3 and $8 \mathrm{hr})$ and late $(24$ and $48 \mathrm{hr})$

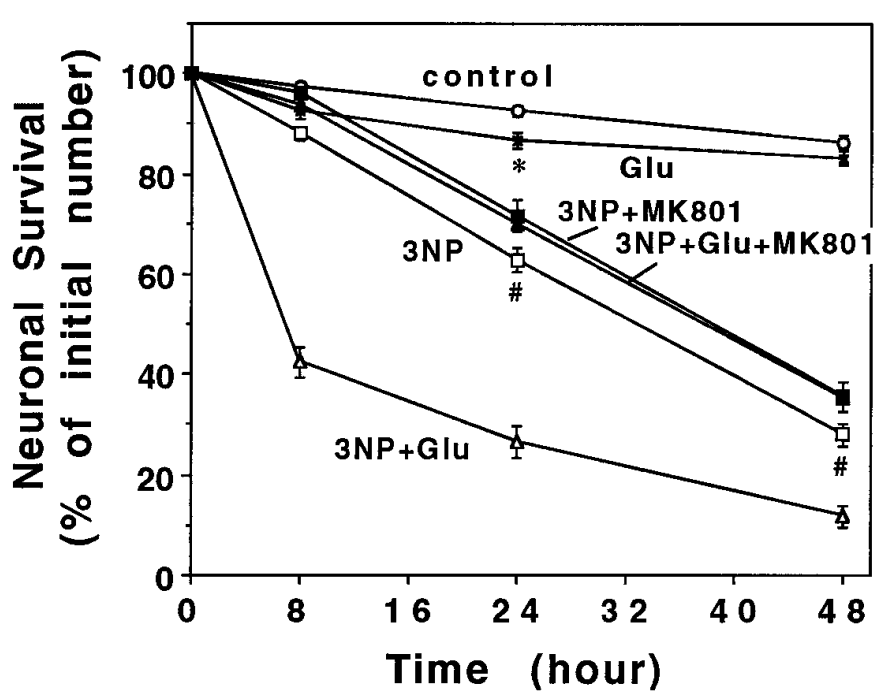

Figure 4. Exogenous glutamate accelerates acute neuronal death. Cultures were subjected to the following treatments: 3-NP alone (open squares), 3-NP plus glutamate (open triangles), 3-NP plus MK-801 (filled squares), 3-NP plus glutamate plus MK-801 (filled triangles), glutamate alone (cross), and change of medium without drug addition (open circles). Drug concentrations were $5 \mathrm{mM} 3-\mathrm{NP}, 10 \mu \mathrm{M}$ MK-801, $1 \mu \mathrm{g} / \mathrm{ml} \mathrm{CHX}$, and $10 \mu \mathrm{M}$ glutamate. Results are the mean \pm SEM of 10-16 cultures. Note that MK-801 did not alter the rate of delayed cell death. *, significantly different from control, $p<0.01$; \#, significantly different from 3-NP plus MK801, $p<0.05$.

time points, allowing for the identification of both acute and delayed cell death. Morphologically, the acute cell death resulted in nuclear shrinkage without fragmentation and rapid cell body swelling and cell lysis, typical of necrotic cell death (Wyllie et al., 1980). In contrast, the delayed cell death led to nuclear fragmentation without cell body swelling, indicative of apoptosis. Pharmacologically, the acute necrosis could be effectively blocked by MK-801 and dose-dependently potentiated by exogenous glutamate, therefore attributable to NMDA receptor activity. The delayed apoptosis was prevented by cycloheximide but not by MK-801, indicating that the delayed cell death was not simply a delayed excitotoxicity. Taken together, our data strongly suggest that there are two neuronal death mechanisms in 3-NP neurotoxicity: apoptosis and excitotoxic necrosis.

Whether excitotoxic neuronal cell death is apoptotic or necrotic has been the subject of controversy. The initial evidence for an apoptotic mechanism was that internucleosomal DNA fragmentation was triggered by glutamate in cultured cortical neurons (Kure et al., 1991). However, later studies showed that this could be attributable to decreased glutathione instead of the conventional receptor-mediated toxicity (Murphy et al., 1989; Ratan et al., 1994). Other reports argue against an apoptotic mechanism (Dessi et al., 1993; Csernansky et al., 1994). Making the issue more complicated are reports that glutamate-induced cell death could be either apoptotic or necrotic depending on the intensity of stimuli (Bonfoco et al., 1995) or the ability of neurons to recover mitochondrial membrane potential (Ankarcrona et al., 1995). However, it is uncertain whether the presumed apoptosis did indeed result from glutamate receptor activation or merely reflected background apoptosis. Moreover, it has been speculated that excitotoxicity may display both apoptotic (e.g., DNA laddering) and necrotic features (e.g., DNA smearing and organelle swelling) (Portera-Cailliau et al., 1995). 

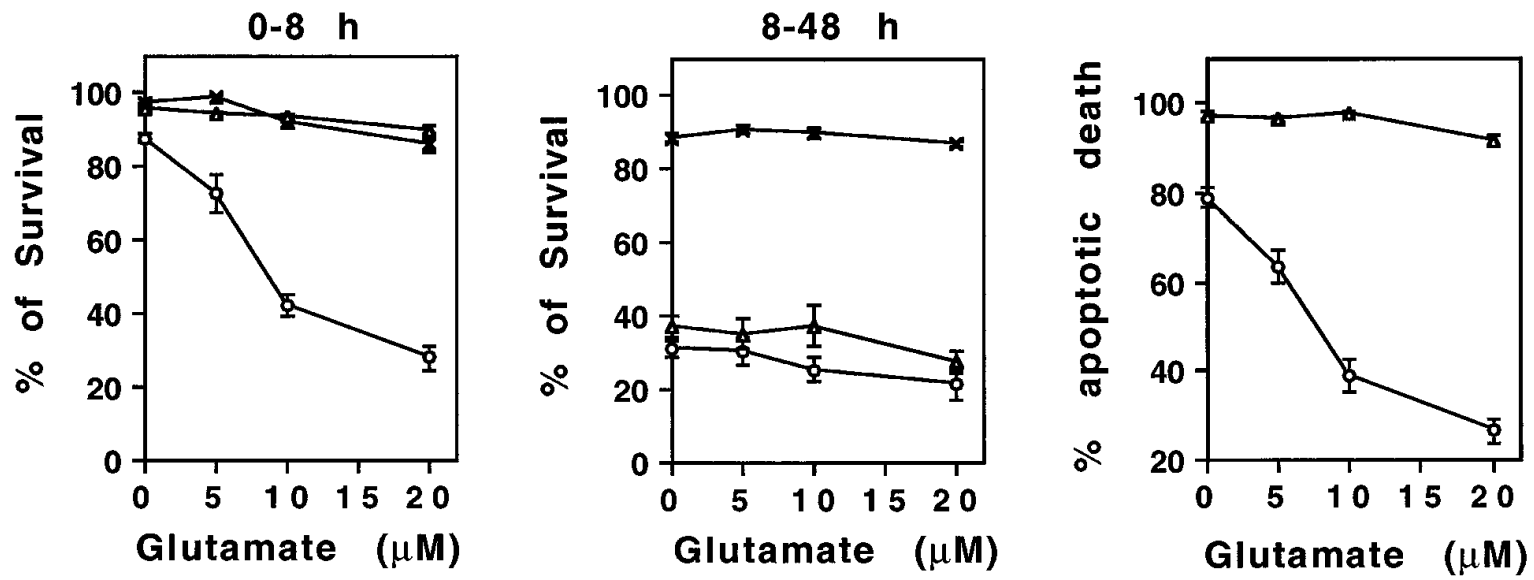

Figure 5. Extracellular glutamate affects neuronal survival in a dose-dependent manner. The acute cell death within the first $8 \mathrm{hr}(A)$, but not the delayed cell death between the 8 and $48 \mathrm{hr}$ time points $(B)$, is glutamate concentration-dependent. Cultures were treated with glutamate alone (cross) and with 3-NP ( $5 \mathrm{mM}$ ) plus varying concentrations of glutamate in the absence (circles) or presence (triangles) of MK-801 (10 $\mu \mathrm{M})$. Apoptosis was quantified at the $48 \mathrm{hr}$ time point. Glutamate reduced the percentage of apoptotic cell death $(C)$. Results are the mean \pm SEM of $10-16$ cultures.

The somewhat confounding data and interpretations derived from these studies may be partially attributable to the criteria used to identify apoptosis. Some of the criteria, such as the size of the nucleus (Ankarcrona et al., 1995) and DNA fragmentation (Collins et al., 1992; Oberhammer et al., 1993; Portera-Cailliau et al., 1995), may not be specific for apoptosis. In our experiments, apoptotic cells were identified as cells exhibiting nuclear fragmentation, a hallmark of apoptosis in different cell types and in response to a variety of stimuli (Lazebnik et al., 1993; Oberhammer et al., 1993). We found that cell death under normal culture conditions was entirely apoptotic, reminiscent of naturally occurring cell death during development. After 3-NP treatment, cell death resulted in either nuclear shrinkage or nuclear fragmentation, corresponding to excitotoxic necrosis or apoptosis, respectively. However, this does not exclude the possibility that necrosis and apoptosis may express different spectra of characteristics in other models.

TUNEL techniques have been used extensively to identify cells containing damaged DNA, especially in numerous in vivo experiments. However, the specificity of TUNEL for apoptosis is questionable (Portera-Cailliau et al., 1995; Anderson et al., 1996). Our data show that fragmented nuclei resulting from apoptosis are inevitably labeled with TUNEL, whereas the necrotic nuclei resulting from excitotoxicity become TUNEL-positive during the postmortem time period. Therefore, depending on when the staining is conducted in relation to the onset of cell death, a TUNEL-positive signal does not always mean apoptosis. Because it is difficult (if not impossible) to perform TUNEL staining immediately after cell death in many circumstances, a combination of nuclear morphology and TUNEL is a more reliable criterion for apoptosis.

We also examined whether DNA fragmentation precedes cell death. No morphologically normal nuclei were TUNEL-positive, indicating that DNA damage at detectable levels is a late event in both apoptosis and necrosis. This is in agreement with previous studies (Oberhammer et al., 1993; Mesner et al., 1995).

The potentiation of excitotoxic necrosis by low levels of extracellular glutamate is relevant to the neuronal damage associated with brain ischemia and age-related neurodegenerative diseases. The results of this and previous studies demonstrate that when energy levels are reduced, even moderate levels of extracellular glutamate can induce excitotoxic cell death (Novelli et al., 1988; Zeevalk and Nicklas, 1991; Fu et al., 1995). In our hippocampal neuronal cultures, the basal level of extracellular glutamate was $4.3 \mu \mathrm{M}$, similar to the estimates of normal extracellular glutamate levels in the CNS and in cultures used by others (Mitani et al., 1990; Dickie et al., 1996; Didier et al., 1996). 3-NP does not result in an increase in extracellular glutamate (Zeevalk and Nicklas, 1991; Beal et al., 1993; Fu et al., 1995). In the absence of added glutamate, 3-NP resulted in $\sim 60 \%$ neuronal loss over $48 \mathrm{hr}$, of which approximately $20 \%$ was necrosis and $80 \%$ apoptosis. A dose-dependent increase in necrotic death was observed when glutamate was added at 5-20 $\mu \mathrm{M}$. These glutamate concentrations are physiologically relevant. Extracellular glutamate levels increase four- to ninefold and may reach $50 \mu \mathrm{M}$ after cerebral ischemia (Globus et al., 1988; Mitani et al., 1990; Buisson et al., 1992; Hashimoto et al., 1994). The results of this study suggest that under ischemic conditions, neuronal cell death would be primarily excitotoxic.

Alteration in mitochondrial functions has been implicated in apoptosis (Petit et al., 1996; Skulachev, 1996). It has been hypothesized that the cellular ATP level is an important determinant for cell death, either by apoptosis or necrosis (Richter et al., 1996). Loss of mitochondrial membrane potential precedes nuclear alteration in nerve growth factor (NGF)-deprived sympathetic neurons (Deckwerth and Johnson, 1993). However, substantial loss of ATP is a very late event in apoptosis in PC12 cells deprived of NGF (Mills et al., 1995).

Our results suggest that the severity of ATP depletion may determine whether neurons undergo apoptosis or necrosis. Treatment with 3 -NP alone resulted in mild ATP loss ( $\sim 20 \%$ loss in 2 $\mathrm{hr}$ ), and the cell death was predominantly apoptotic, whereas 3 -NP plus glutamate resulted in more severe ATP loss ( $\sim 50 \%$ loss in $2 \mathrm{hr}$ ) and rapid necrotic cell death. Glutamate alone had no significant effect on the ATP level, indicating that the severe ATP loss is the result of synergistic effects of inhibition of SDH and activation of glutamate receptors. At least two mechanisms may contribute to this synergism. First, calcium influx may initially stimulate mitochondrial respiration (Hansford, 1985; McCormack et al., 1990; Li et al., 1996). As a suicide inhibitor, 3-NP inactivates 

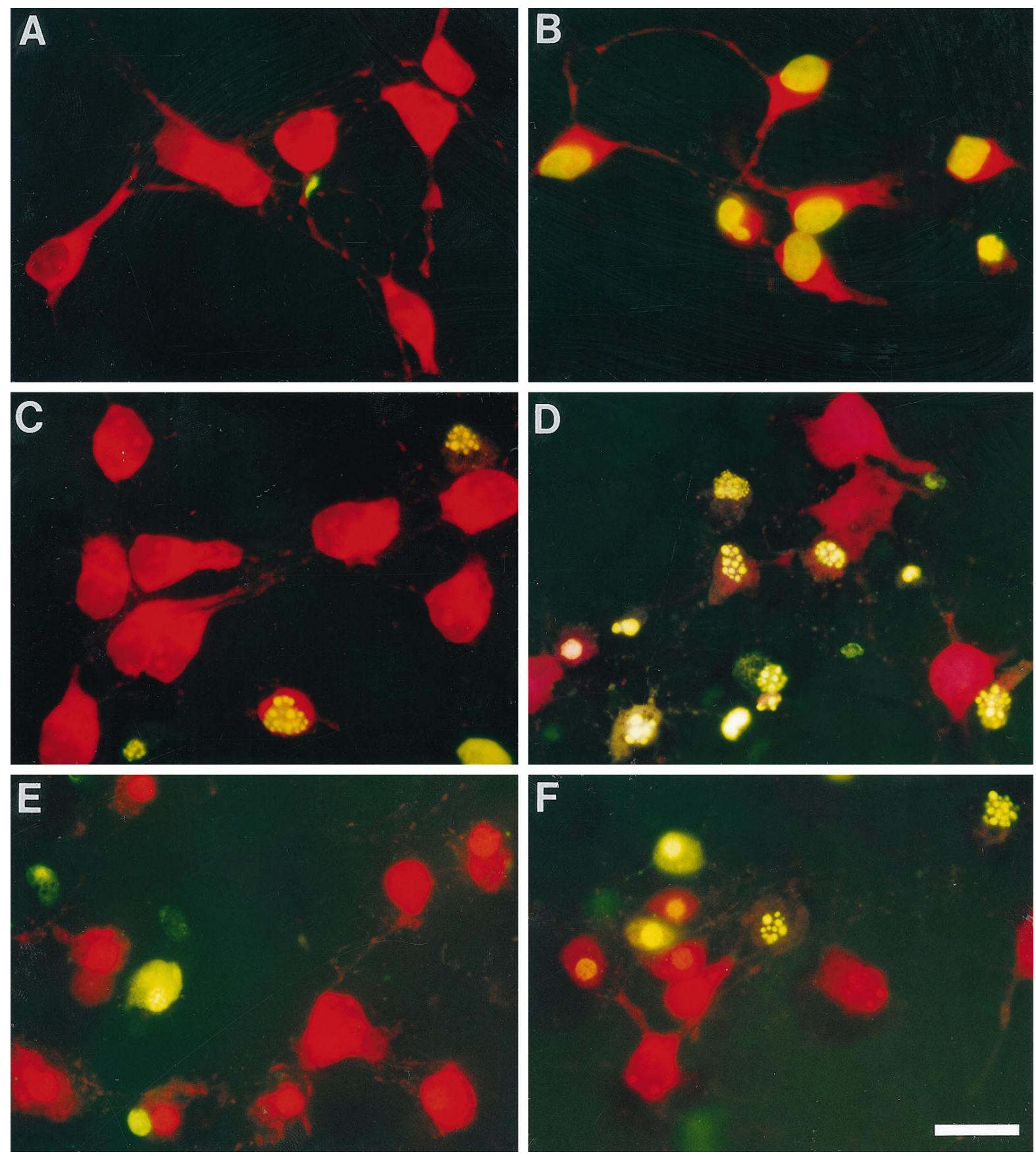

Figure 6. In situ DNA fragmentation detected by the TUNEL technique. Cells were fixed and stained with TUNEL (green) and PI (red). Photos were taken using a triple-band filter. Yellow represents the colocalization of PI staining and TUNEL signal. $A$, Negative control (omission of TdT). $B$, Positive control (DNase I treatment). In untreated cultures $(C)$, apoptotic neuronal death was detected. In cultures treated with 3-NP $(5 \mathrm{mM})$ for $48 \mathrm{hr}(D)$ and with 3-NP (5 mM) plus glutamate $(10 \mu \mathrm{M})$ for $8 \mathrm{hr}(E)$ or $48 \mathrm{hr}(F)$, all apoptotic nuclei were TUNEL-positive. Necrotic nuclei were not TUNEL-positive at $8 \mathrm{hr}$, but were variably decorated at the $48 \mathrm{hr}$ time point. Scale bar, $25 \mu \mathrm{m}$.

SDH more rapidly when the enzyme activity is higher (Alston et al., 1977). Second, calcium and sodium influx may stimulate the consumption of ATP through $\mathrm{Ca}^{2+}$-ATPase and $\mathrm{Na}^{+} / \mathrm{K}^{+}$ATPase. Moreover, calcium overload will ultimately disrupt mitochondrial function (Mattson et al., 1993; Medrano and Fox, 1994; Minezaki et al., 1994; Schinder et al., 1996; White and Reynolds, 1996). Cycloheximide has no effect on 3-NP-induced decline in cellular ATP levels, suggesting that loss of ATP is indeed an initial event and that cycloheximide acts downstream to ATP loss.

Our data support an emerging theory proposed by Choi (1995) that apoptotic and necrotic mechanisms may coexist within individual degenerating neurons after metabolic insults, and that the former may be masked by a rapid excitotoxic necrosis (Gwag et al., 1995). This is particularly relevant to conditions in which there are both metabolic impairment and an elevation in extracellular 
A

Figure 7. Time-dependent increase in DNA fragmentation (TUNEL staining) after necrotic cell death. Cultures were treated with $3-\mathrm{NP}(5 \mathrm{~mm})$ and glutamate $(10 \mu \mathrm{M})$ for the indicated time period and double-labeled with TUNEL and PI. $A$, The percentage of TUNEL-positive necrotic neurons increased dramatically between 3 and $48 \mathrm{hr}$. $B$, The percentage of necrotic cells (vs total cells) did not change significantly during this time period. Approximately 150 cells per culture were sampled randomly. Results are the mean $\pm \operatorname{SEM}(n=3)$. Significantly different from the 3 and $8 \mathrm{hr}$ values $\left({ }^{*} p<0.05,{ }^{* *} p<0.01\right)$.

\section{$\begin{array}{r}\frac{0}{9} \\ 0 \\ \frac{0}{0} \\ + \\ \hline \\ \hline \\ \hline \\ \hline\end{array}$}

B

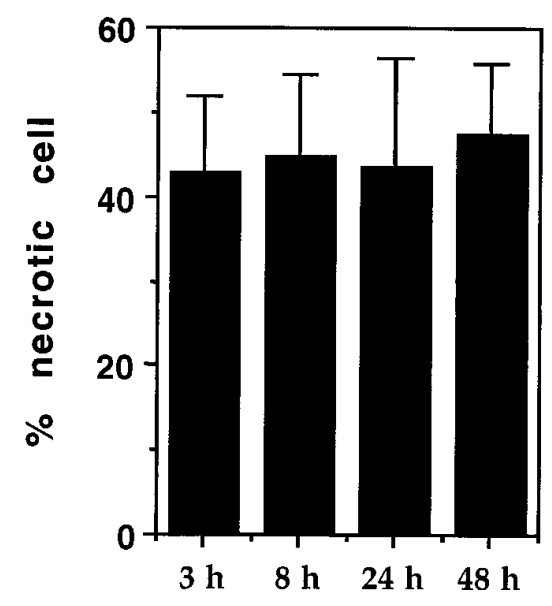

Figure 8. Cellular ATP levels after treatment with 3-NP. A, Time course of alterations in cellular ATP levels after treatment with 3-NP (5 mM) alone (circles) or with 3-NP (5 mM) plus MK-801 $(10 \mu \mathrm{M})$ (triangles). Significantly different from 3-NP alone at the corresponding time point $\left({ }^{*} p<0.05,{ }^{* *} p<0.01\right)$. $B$, Cellular ATP levels $2 \mathrm{hr}$ after the indicated treatments. Drug concentrations were $5 \mathrm{~mm} 3-\mathrm{NP}, 10 \mu \mathrm{M}$ MK-801, 1 $\mu \mathrm{g} / \mathrm{ml} \mathrm{CHX}$, and $10 \mu \mathrm{M}$ glutamate. Results are the mean \pm SEM of at least six cultures. Significantly different from control $\left({ }^{*} p<0.05,{ }^{* *} p<0.01\right)$. \#, significantly different from 3 -NP plus glutamate, $p<0.05$.
A

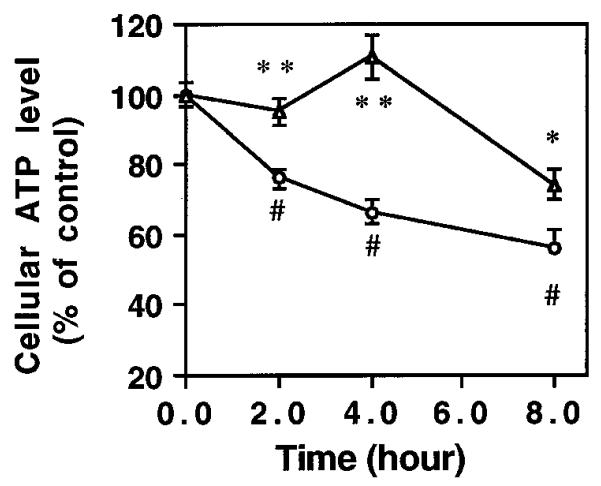

B

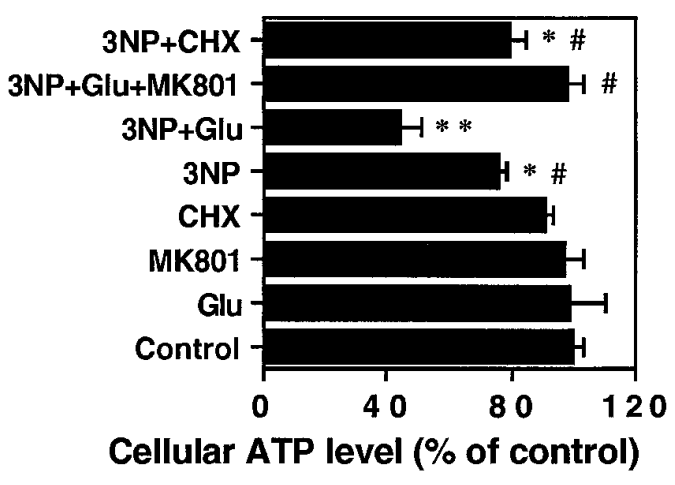

glutamate, such as ischemia. Under these conditions, attenuation of neuronal death requires interventions directed against both excitotoxicity and apoptosis.

Our data suggest that mild metabolic impairment, in the absence of an elevation in extracellular glutamate, can activate an apoptotic mechanism. This set of conditions may be relevant to neurodegenerative diseases. In Huntington's disease, the increased polyglutamine repeat in huntingtin protein may contribute to a decrease in energy metabolism (Cha and Dure, 1994). 3 -NP has been used in rodents and primates to model Huntington's disease (Beal, 1994). Decreased energy metabolism is also evident in Alzheimer's disease (Beal, 1995). Recent findings indicate that a primary target of $\beta$-amyloid peptide is SDH (Kaneko et al., 1995) and that $\beta$-amyloid peptide results in the loss of energy homeostasis (Zhang et al., 1996). Moreover, $\beta$-amyloid can induce apoptotic neuronal death (Loo et al., 1993) and exacerbate glutamate toxicity (Koh et al., 1990; Mattson et al., 1992). The 3-NP model established in the current study is therefore relevant to acute insults such as ischemia, as well as neurodegenerative disorders, including Huntington's disease and Alzheimer's disease.

\section{REFERENCES}

Alston TA, Mela L, Bright HJ (1977) 3-Nitropropionate, the toxic substance of Indiofera, is a suicide inactivator of succinate dehydrogenase. Proc Natl Acad Sci USA 74:3767-3771.

Anderson AJ, Su JH, Cotman CW (1996) DNA damage and apoptosis in
Alzheimer's disease: colocalization with c-Jun immunoreactivity, relationship to brain area, and effect of postmortem delay. J Neurosci 16:1710-1719.

Ankarcrona M, Dypbukt JM, Bonfoco E, Zhivotovsky B, Orrenius S, Lipton SA, Nicotera P (1995) Glutamate-induced neuronal death: a succession of necrosis or apoptosis depending on mitochondrial function. Neuron 15:961-973.

Beal MF (1992) Does impairment of energy metabolism result in excitotoxic neuronal death in neurodegenerative illnesses? Ann Neurol 31:119-130.

Beal MF (1994) Neurochemistry and toxin models in Huntington's disease. Curr Opin Neurol 7:542-547.

Beal MF (1995) Aging, energy, and oxidative stress in neurodegenerative diseases. Ann Neurol 38:357-366.

Beal MF, Brouillet E, Jenkins BG, Ferrante RJ, Kowall NW, Miller JM, Storey E, Srivastava R, Rosen BR, Hyman BT (1993) Neurochemical and histologic characterization of striatal excitotoxic lesions produced by the mitochondrial toxin 3-nitropropionic acid. J Neurosci 13:4181-4192.

Behrens MI, Koh J, Canzoniero LMT, Sensi SL, Csernansky CA, Choi DW (1995) 3-Nitropropionic acid induces apoptosis in cultured striatal and cortical neurons. NeuroReport 6:545-548.

Bonfoco E, Krainc D, Ankarcrona M, Nicotera P, Lipton SA (1995) Apoptosis and necrosis: two distinct events induced, respectively, by mild and intense insults with $N$-methyl-D-aspartate or nitric oxide/ superoxide in cortical cell cultures. Proc Natl Acad Sci USA 92:7162-7166.

Bredesen DE (1995) Neuronal apoptosis. Ann Neurol 38:839-851.

Brewer GJ, Torricelli JR, Evege EK, Price PJ (1993) Optimized survival of hippocampal neurons in B27-supplemented Neurobasal, a new serum-free medium combination. J Neurosci Res 35:567-576. 
Buisson A, Callebert J, Mathieu E, Plotkine M, Boulu RG (1992) Striatal protection induced by lesioning the substantia nigra of rats subjected to focal ischemia. J Neurochem 59:1153-1157.

Cha JH, Dure 4th LS (1994) Trinucleotide repeats in neurological diseases: an hypothesis concerning the pathogenesis of Huntington's disease, Kennedy's disease, and spinocerebellar ataxia type I. Life Sci 54:1459-1464.

Choi DW (1995) Calcium: still center-stage in hypoxic-ischemic neuronal death. Trends Neurosci 18:58-60.

Chopp M, Li Y (1996) Apoptosis in focal cerebral ischemia. Acta Neurochir Suppl (Wien) 66:21-26.

Collins RJ, Harmon BV, Gobe GC, Kerr JF (1992) Internucleosomal DNA cleavage should not be the sole criterion for identifying apoptosis. Int J Radiat Biol 61:451-453.

Cotman CW, Anderson AJ (1995) A potential role for apoptosis in neurodegeneration and Alzheimer's disease. Mol Neurobiol 10:19-45.

Csernansky CA, Canzoniero LM, Sensi SL, Yu SP, Choi DW (1994) Delayed application of aurintricarboxylic acid reduces glutamateinduced cortical neuronal injury. J Neurosci Res 38:101-108.

Deckwerth TL, Johnson EM (1993) Temporal analysis of events associated with programmed cell death (apoptosis) of sympathetic neurons deprived of nerve growth factor. J Cell Biol 123:1207-1222.

Dessi F, Charriaut-Marlangue C, Khrestchatisky M, Ben-Ari Y (1993) Glutamate-induced neuronal death is not a programmed cell death in cerebellar culture. J Neurochem 60:1953-1955.

Dickie BGM, Holmes C, Greenfield SA (1996) Neurotoxic and neurotrophic effects of chronic $N$-methyl-D-aspartate exposure upon mesencephalic dopaminergic neurons in organotypic culture. Neuroscience 72:731-741.

Didier M, Bursztajn S, Adamec E, Passani L, Nixon RA, Coyle JT, Wei JY, Berman SA (1996) DNA strand breaks induced by sustained glutamate excitotoxicity in primary neuronal cultures. J Neurosci 16:2238-2250.

Du C, Hu R, Csernansky CA, Hsu CY, Choi DW (1996) Very delayed infarction after mild focal cerebral ischemia: a role for apoptosis? J Cereb Blood Flow Metab 16:195-201.

Fink SL, Ho DY, Sapolsky RM (1996) Energy and glutamate dependency of 3-nitropropionic acid neurotoxicity in culture. Exp Neurol 138:298-304.

Fu Y, He F, Zhang S, Huang J, Zhang J, Jiao X (1995) 3-Nitropropionic acid produces indirect excitotoxic damage to rat striatum. Neurotoxicol Teratol 17:333-339.

Gavrieli Y, Sherman Y, Ben-Sasson SA (1992) Identification of programmed cell death in situ via specific labeling of nuclear DNA fragmentation. J Cell Biol 119:493-501.

Globus MY-T, Busto R, Dietrich WD, Martinez E, Valdes I, Ginsberg MD (1988) Effect of ischemia on the in vivo release of striatal dopamine, glutamate, and gamma-aminobutyric acid studied by intracerebral microdialysis. J Neurochem 51:1455-1464.

Greene JG, Greenamyre JT (1995) Exacerbation of NMDA, AMPA, and L-glutamate excitotoxicity by the succinate dehydrogenase inhibitor malonate. J Neurochem 64:2332-2338.

Gwag BJ, Lobner D, Koh JY, Wie MB, Choi DW (1995) Blockade of glutamate receptors unmasks neuronal apoptosis after oxygen-glucose deprivation in vitro. Neuroscience 68:615-619.

Hansford RG (1985) Relation between mitochondrial calcium transport and control of energy metabolism. Rev Physiol Biochem Pharmacol 102:1-72.

Hashimoto N, Matsumoto T, Mabe H, Hashitani T, Nishino H (1994) Dopamine has inhibitory and accelerating effects on ischemia-induced neuronal cell damage in the rat striatum. Brain Res Bull 33:281-288.

Kaneko I, Yamada N, Sakuraba Y, Kamenosono M, Tutumi S (1995) Suppression of mitochondrial succinate dehydrogenase, a primary target of $\beta$-amyloid, and its derivative racemized at Ser residue. J Neurochem 65:2585-2593.

Koh J-Y, Yang LL, Cotman CW (1990) $\beta$-amyloid protein increases the vulnerability of cultured cortical neurons to excitotoxic damage. Brain Res 533:315-320.

Kure S, Tominaga T, Yoshimoto T, Tada K, Narisawa K (1991) Glutamate triggers internucleosomal DNA cleavage in neuronal cells. Biochem Biophys Res Commun 179:39-45.

Lassmann H, Bancher C, Breitschopf H, Wegiel J, Bobinski M, Jellinger K, Wisniewski HM (1995) Cell death in Alzheimer's disease evaluated by DNA fragmentation in situ. Acta Neuropathol (Berl) 89:35-41.
Lazebnik YA, Cole S, Cooke CA, Nelson WG, Earnshaw WC (1993) Nuclear events of apoptosis in vitro in cell-free mitotic extracts: a model system for analysis of the active phase of apoptosis. J Cell Biol 123:7-22.

Li HL, Wu S, Rottenberg H (1996) Alcohol inhibits the depolarizationinduced stimulation of oxidative phosphorylation in synaptosomes. J Neurochem 66:1691-1697.

Loo D, Copani A, Pike C, Whittemore E, Walencewicz A, Cotman CW (1993) Apoptosis is induced by beta-amyloid in cultured central nervous system neurons. Proc Natl Acad Sci USA 90:7951-7955.

Majno G, Joris I (1995) Apoptosis, oncosis, and necrosis: an overview of cell death. Am J Pathol 146:3-15.

Maragos WF, Silverstein FS (1995) The mitochondrial inhibitor malonate enhances NMDA toxicity in the neonatal rat striatum. Dev Brain Res 88:117-121.

Marey-Semper I, Gelman M, Levi-Strauss M (1995) A selective toxicity toward cultured mesencephalic dopaminergic neurons is induced by the synergistic effects of energetic metabolism impairment and NMDA receptor activation. J Neurosci 15:5912-5918.

Martin DP, Schmidt RE, DiStefano PS, Lowry OH, Carter JG, Johnson EJ (1988) Inhibitors of protein synthesis and RNA synthesis prevent neuronal death caused by nerve growth factor deprivation. J Cell Biol 106:829-844.

Mattson MP, Cheng B, Davis D, Bryant K, Lieberburg I, Rydel RE (1992) $\beta$-Amyloid peptides destabilize calcium homeostasis and render human cortical neurons vulnerable to excitotoxicity. J Neurosci 12:379-389.

Mattson MP, Zhang Y, Bose S (1993) Growth factors prevent mitochondrial dysfunction, loss of calcium homeostasis, and cell injury, but not ATP depletion in hippocampal neurons deprived of glucose. Exp Neurol 121:1-13.

McCormack JG, Halestrap AP, Denton RM (1990) Role of calcium ions in regulation of mammalian intramitochondrial metabolism. Physiol Rev 70:391-425.

Medrano CJ, Fox DA (1994) Substrate-dependent effects of calcium on rat retinal mitochondrial respiration: physiological and toxicological studies. Toxicol Appl Pharmacol 125:309-321.

Mesner PW, Epting CL, Hegarty JL, Green SH (1995) A timetable of events during programmed cell death induced by trophic factor withdrawal from neuronal PC12 cells. J Neurosci 15:7357-7366.

Mills JC, Nelson D, Erecinska M, Pittman RN (1995) Metabolic and energetic changes during apoptosis in neural cells. J Neurochem 65:1721-1730.

Minezaki KK, Suleiman MS, Chapman RA (1994) Changes in mitochondrial function induced in isolated guinea-pig ventricular myocytes by calcium overload. J Physiol (Lond) 476:459-471.

Mitani A, Kubo H, Iga K, Imon H, Kadoya F, Kataoka K (1990) A new enzymatic cycling technique for glutamate determination in brain microdialysates. J Neurochem 54:709-711.

Murphy TH, Miyamoto M, Sastre A, Schnaar RL, Coyle JT (1989) Glutamate toxicity in a neuronal cell line involves inhibition of cystine transport leading to oxidative stress. Neuron 2:1547-1558.

Nitatori T, Sato N, Waguri S, Karasawa Y, Araki H, Shibanai K, Kominami E, Uchiyama Y (1995) Delayed neuronal death in the CA1 pyramidal cell layer of the gerbil hippocampus following transient ischemia is apoptosis. J Neurosci 15:1001-1011.

Novelli A, Reilly JA, Lysko PG, Henneberry RC (1988) Glutamate becomes neurotoxic via the $N$-methyl-D-aspartate receptor when intracellular energy levels are reduced. Brain Res 451:205-212.

Oberhammer F, Fritsch G, Schmied M, Pavelka M, Printz D, Purchio T, Lassmann H, Schulte HR (1993) Condensation of the chromatin at the membrane of an apoptotic nucleus is not associated with activation of an endonuclease. J Cell Sci 104:317-326.

Petit PX, Susin SA, Zamzami N, Mignotte B, Kroemer G (1996) Mitochondria and programmed cell death: back to the future. FEBS Lett 396:7-13.

Portera-Cailliau C, Hedreen JC, Price DL, Koliatsos VE (1995) Evidence for apoptotic cell death in Huntington disease and excitotoxic animal models. J Neurosci 15:3775-3787.

Ratan RR, Murphy TH, Baraban JM (1994) Oxidative stress induces apoptosis in embryonic cortical neurons. J Neurochem 62:376-379.

Richter C, Schweizer M, Cossarizza A, Franceschi C (1996) Control of apoptosis by the cellular ATP level. FEBS Lett 378:107-110.

Schinder AF, Olson EC, Spitzer NC, Montal M (1996) Mitochondrial dysfunction is a primary event in glutamate neurotoxicity. J Neurosci 16:6125-6133. 
Skulachev VP (1996) Why are mitochondria involved in apoptosis? Permeability transition pores and apoptosis as selective mechanisms to eliminate superoxide-producing mitochondria and cell. FEBS Lett 397:7-10.

Wallace DC (1994) Mitochondrial DNA mutations in diseases of energy metabolism. J Bioenerg Biomembr 26:241-250.

Weller M, Paul SM (1993) 3-Nitropropionic acid is an indirect excitotoxin to cultured cerebellar granule neurons. Eur J Pharmacol 248:223-228.

White RJ, Reynolds IJ (1996) Mitochondrial depolarization in glutamate-stimulated neurons: an early signal specific to excitotoxin exposure. J Neurosci 16:5688-5697.
Wyllie AH, Kerr JF, Currie AR (1980) Cell death: the significance of apoptosis. Int Rev Cytol 68:251-306.

Wyllie AH, Morris RG, Smith AL, Dunlop D (1984) Chromatin cleavage in apoptosis: association with condensed chromatin morphology and dependence on macromolecular synthesis. J Pathol 142:67-77.

Zeevalk GD, Nicklas WJ (1991) Mechanisms underlying initiation of excitotoxicity associated with metabolic inhibition. J Pharmacol Exp Ther 257:870-878.

Zhang Z, Rydel RE, Drzewiecki GJ, Fuson K, Wright S, Wogulis M, Audia JE, May PC, Hyslop PA (1996) Amyloid $\beta$-mediated oxidative and metabolic stress in rat cortical neurons: no direct evidence for a role for $\mathrm{H}_{2} \mathrm{O}_{2}$ generation. J Neurochem 67:1595-1606. 